\title{
TERMINATION OF A CIVIL CONTRACT DUE TO A SIGNIFICANT CHANGE IN CIRCUMSTANCES: LEGISLATION AND PRACTICE OF POST-SOVIET STATES
}

\author{
Mohammed Vidad Abdulhamid Alhamdawi \\ Volgograd State University, Volgograd, Russian Federation \\ Maxim M. Nenashev \\ PAO “Nizhnekamskneftekhim”, Nizhnekamsk, Russian Federation
}

\begin{abstract}
Introduction: the scientific interest in the study of peculiarities of regulating the termination of a civil contract due to a significant change in circumstances in the foreign practice is predetermined by both the discussion and lack of scientific coverage of the relevant issues, and the difficulties in interpreting and applying the relevant norms of the law of obligations in Russia. Methods: the methodological framework for the research is a set of methods of scientific cognition, among which the main ones are the general scientific dialectical, comparative legal, logical-syntactic, semantic methods of cognition, as well as the methods of cause-and-effect analysis, forecasting, synthesis and analysis. Results: the study reveals the features and main problematic aspects of the application of the rules on the termination of a civil contract due to a significant change in circumstances in a number of post-Soviet states. The paper presents the insights on the need to improve the statutory regulation of the considered grounds for the termination of a civil contract in Russia, including specifying the provisions of Article 451 of the Civil Code.
\end{abstract}

Key words: civil contract, dissolution of a contract, termination of a contract, contract law, significant change in circumstances

Citation. Alhamdawi Mohammed Vidad Abdulhamid, Nenashev M.M. Termination of a Civil Contract Due to a Significant Change in Circumstances: Legislation and Practice of Post-Soviet States. Legal Concept = Pravovaya paradigma, 2020, vol. 19, no. 4, pp. 43-47. (in Russian). DOI: https://doi.org/10.15688/ lc.jvolsu.2020.4.5

\section{РАСТОРЖЕНИЕ ГРАЖДАНСКО-ПРАВОВОГО ДОГОВОРА В СВЯЗИ С СУЩЕСТВЕННЫМ ИЗМЕНЕНИЕМ ОБСТОЯТЕЛЬСТВ: ЗАКОНОДАТЕЛЬСТВО И ПРАКТИКА ПОСТСОВЕТСКИХ ГОСУДАРСТВ}

\author{
Мохаммед Видад Абдулхамид Альхамдави \\ Волгоградский государственный университет, г. Волгоград, Российская Федерация \\ Максим Михайлович Ненашев \\ ПАО «Нижнекамскнефтехим», г. Нижнекамск, Российская Федерация
}

Введение: научный интерес к исследованию особенностей регулирования расторжения гражданскоправового договора в связи с существенным изменением обстоятельств в зарубежной практике предопределен как дискуссионностью и пробельностью научного освещения соответствующей проблематики, так и сложностями толкования и применения соответствующих норм обязательственного права в России. Мето- 
ды: методологическую основу данного исследования составляет совокупность методов научного познания, среди которых основное место занимают общенаучный - диалектический, сравнительно-правовой, логикосинтаксический, семантический методы познания, а также методы причинно-следственного анализа, прогнозирования, синтеза и анализа. Результаты: в исследовании выявлены особенности и основные проблемные аспекты применения норм о расторжении гражданско-правового договора в связи с существенным изменением обстоятельств в ряде государств постсоветского пространства. В статье обосновываются выводы о необходимости совершенствования нормативного регулирования рассматриваемого основания расторжения гражданско-правового договора в России, в том числе конкретизации положений ст. 451 ГК РФ.

Ключевые слова: гражданско-правовой договор, расторжение договора, прекращение договора, договорное право, существенное изменение обстоятельств.

Цитирование. Альхамдави Мохаммед Видад Абдулхамид, Ненашев М. М. Расторжение гражданскоправового договора в связи с существенным изменением обстоятельств: законодательство и практика постсоветских государств // Legal Concept = Правовая парадигма. - 2020. - Т. 19, № 4. - С. 43-47. - DOI: https:// doi.org/10.15688/lc.jvolsu.2020.4.5

\section{Введение}

Вопросы исследования практических аспектов расторжения гражданско-правового договора в связи с существенным изменением обстоятельств в современной российской цивилистике традиционно являются предметом дискуссий, что опосредовано как наличием ряда инициатив по совершенствованию регламентирующих данные вопросы норм законодательства, так и сложностями обеспечения их единообразного применения. Изложенные причины предопределяют значимость изучения сравнительно-правовых аспектов расторжения договоров по рассматриваемому основанию, в том числе на примере постсоветских государств, правовые системы которых в наибольшей степени близки российской - тем более, что данная проблематика, как ввиду комплексного характера, так и в силу динамизма развития правоприменительной практики, а также определенной новизны для соответствующих национальных правовых систем, исследована пока далеко не исчерпывающим образом.

\section{Легальные дефиниции существенного изменения обстоятельств}

Рассматриваемый правовой институт появился в российском законодательстве уже в постсоветский период, с принятием в 1994 г. первой части ГК [9, с. 3]. Исходя из абз. 2 п. 1 ст. 451 ГК РФ, текст которой в течение 26 лет действия остался неизменным, «изменение обстоятельств признается существенным, когда они изменились настолько, что, если бы стороны могли это разумно предвидеть, договор вообще не был бы ими заключен или был бы заключен на значительно отличающихся условиях» [7]. Приведенная формулировка дословно (за исключением замены подчинительного союза «когда» на если») воспроизводится в ст. 421 ГК Республики Беларусь [5] и в ст. 412 ГК Кыргызстана [4], тогда как в гражданских кодексах ряда других стран постсоветского пространства текстуальные отличия более значимы и заслуживают отдельного внимания.

Так, в ст. 652 ГК Украины [8] аналогичная норма изложена без указания «разумности» предвидения, а также «значительности» отличия условий, что, с одной стороны, «разгружает» статью закона от сложных оценочных конструкций, с другой - как представляется, делает ее содержание еще менее определенным. Статья 422 ГК Азербайджана [3] текстуально близка упомянутой норме ГК РФ, однако приравнивает к объективным условиям изменения обстоятельств также и субъективное - ошибочность представлений сторон, лежащих в основе договора (как отмечается в компаративистских исследованиях, наличие такой оговорки характерно также для германского права [2]). Во всех же иных случаях, как видно из изложенного, речь идет об обстоятельствах, «внешних» для договорного правоотношения.

Наконец, есть на постсоветском пространстве и примеры отсутствия соответствующих норм, чем отличается ГК Казахстана [6]. 


\section{Проблематика расторжения договора по рассматриваемому основанию}

Проанализированные выше законодательные положения применительно к возможности расторжения гражданско-правового договора вызывают ряд сложностей в практической плоскости, оставаясь не в полной мере востребованными (так, суды ограничиваются, как правило, общими ссылками на соответствующие нормы; отмечаются лишь единичные примеры их применения, тогда как практика инициирования споров с соответствующим правовым основанием существенно шире, касаясь, в частности, вопросов расторжения валютных кредитов в свете финансовых кризисов последнего десятилетия и т. п.). При этом, во всех упомянутых государствах (за исключением, соответственно, Казахстана) предусматривается, что изменение договора по рассматриваемому основанию допускается по решению суда в исключительных случаях.

Тем самым национальные законодатели на постсоветском пространстве исходят из акцента на прекращении договора, как приоритетного перед его адаптацией (что, в свою очередь, можно характеризовать как региональную тенденцию, особенно ярко выраженную в белорусском законодательстве [1, c. 158], но отнюдь не мировую: законодательство и практика ряда развитых государств Запада исходит из обратного [2]). Думается, что названное обстоятельство выступает одним из факторов, искусственно ограничивающих спектр ситуаций применения соответствующих норм, наряду с превалирующим отрицательным отношением к судебному вмешательству в договорные отношения [10, с. 127] и необходимостью установления судами одновременного наличия ряда ограничительных условий (в большинстве рассмотренных государств, как и в п. 2 ст. 451 ГК РФ, их насчитывается 4).

\section{Выводы}

Проведенное исследование позволяет заметить, что гражданское законодательство как России, так и иных постсоветских государств в целом придерживается единых под- ходов к регламентации расторжения договора по рассматриваемому основанию, что прослеживается в сходстве легальных дефиниций такого изменения, условий возможного расторжения или изменения (в исключительных случаях) договора в судебном порядке. При этом, вопреки последней отмеченной тенденции, думается, что предпочтительным правовым последствием при существенном изменении обстоятельств будет все же изменение договора, а не его расторжение, что обусловлено общими потребностями сохранения стабильности гражданского оборота и договорных отношений, благоприятствования развитию последних.

Анализируя соответствующую зарубежную практику на предмет возможной актуализации в России для целей совершенствования конструкции ст. 451 ГК РФ, видится уместным использование азербайджанского опыта введения субъективного условия существенного изменения обстоятельств в связи с ошибкой сторон. В то же время не видятся в данном контексте продуктивными ни украинский подход к минимизации в аналогичной норме оценочных понятий (как еще более снижающий степень определенности ее содержания), ни казахстанский, предполагающий отсутствие рассматриваемого правового института (ведь практический запрос субъектов гражданского оборота на его применение сомнений не вызывает). В этой связи основным вектором положительных изменений в применении положений ст. 451 ГК РФ в России видится развитие практических рекомендаций на уровне Верховного Суда РФ как в части квалификации соответствующих оценочных понятий, так и в плане формулирования примерного (безусловно, открытого) перечня обстоятельств, которые необходимо считать существенно изменившимися.

\section{СПИСОК ЛИТЕРАТУРЫ}

1. Авдеева, Т. В. Расторжение нарушенного договора: совершенствование законодательной модели / Т. В. Авдеева // Общество, право, личность. Методологические и прикладные проблемы: генезис, современность и будущее : сб. ст. Междунар. науч.практ. конф. - Минск : МИТСО, 2017. - С. 158-162. 
2. Алиев, А. Ограничение свободы договора при существенном изменении обстоятельств в английском, немецком, российском и азербайджанском праве / А. Алиев // Вестник Института законодательства и правовой информации Республики Казахстан. 2017. - № 2 (47). - Электрон. текстовые дан. - Режим доступа: https://cyberleninka.ru/article/n/ogranicheniesvobody-dogovora-pri-suschestvennom-izmeneniiobstoyatelstv-v-angliyskom-nemetskom-rossiyskom-iazerbaydzhanskom-prave (дата обращения: 01.09.2020). Загл. с экрана.

3. Гражданский кодекс Азербайджанской Республики от 28.12.1999 г. № 779-IQ // Сборник законодательных актов Азербайджанской Республики. 2000. - № 4. - Ст. 250.

4. Гражданский кодекс Кыргызской Республики от 08.05.1996 г. № 15. Ч. I. - Электрон. текстовые дан. - Режим доступа: http://minjust.gov.kg/ru/ content/313 (дата обращения: 01.09.2020). - Загл. с экрана.

5. Гражданский кодекс Республики Беларусь от 07.12.1998 г. № 218-3. - Электрон. текстовые дан. Режим доступа: https://kodeksy-by.com/grazhdanskij_ kodeks_rb.htm (дата обращения: 01.09.2020).- Загл. с экрана.

6. Гражданский кодекс Республики Казахстан (Общая часть) от 27.12.1994 г. - Электрон. текстовые дан. - Режим доступа: https://online.zakon.kz/ document/?doc_id=1006061\#pos=5;-106 (дата обращения: 01.09.2020). - Загл. с экрана.

7. Гражданский кодекс Российской Федерации (часть первая) от 30.11.1994 г. № 51-Ф3 // Собрание законодательства РФ. - 1994. - 5 дек. -№ 32. - Ст. 3301.

8. Гражданский кодекс Украины от 16.01.2003 г. № 435-IV. - Электрон. текстовые дан. Режим доступа: https://kodeksy.com.ua/ka/ grajdanskij_kodeks_ukraini.htm (дата обращения: 01.09.2020). - Загл. с экрана.

9. Очхаев, Т. Г. Изменение и расторжение договора в связи с существенным изменением обстоятельств : дис. ... канд. юрид. наук : 12.00 .03 / Очхаев Тимур Геннадьевич. - М., 2015. - 249 с.

10. Сосипатрова, Н. Е. Толкование гражданско-правовых договоров в зарубежной и российской правовых системах / Н. Е. Сосипатрова, А. Ю. Бурова // Вестник Нижегородского университета им. Н.И. Лобачевского. Серия: Право. 2018. - № 1. - С. 122-129.

\section{REFERENCES}

1. Avdeeva T.V. Rastorzheniye narushennogo dogovora: sovershenstvovaniye zakonodatelnoy modeli [Dissolution of a Breached Contract: Improving the Legislative Model]. Obshchestvo, pravo, lichnost.
Metodologicheskiye i prikladnyye problemy: genezis, sovremennost $i$ budushcheye: sb. st. Mezhdunar. nauch.-prakt. konf. [Society, Law, Personality. Methodological and Applied Problems: Genesis, Modernity and Future: Collection of Articles of the International Scientific and Practical Conference]. Minsk, MITSO, 2017, pp. 158-162.

2. Aliev A. Ogranicheniye svobody dogovora pri sushchestvennom izmenenii obstoyatelstv $\mathrm{V}$ angliyskom, nemetskom, rossiyskom i azerbaydzhanskom prave [Limitation of Freedom of Contract in Case of Substantial Change of Circumstances in English, German, Russian and Azerbaijani Law]. Vestnik Instituta zakonodatelstva $i$ pravovoy informatsii Respubliki Kazakhstan [Bulletin of the Institute of Legislation and Legal Information of the Republic of Kazakhstan], 2017, no. 2 (47). URL: https:// cyberleninka.ru/article/n/ogranichenie-svobody-dogovorapri-suschestvennom-izmenenii-obstoyatelstv-vangliyskom-nemetskom-rossiyskom-i-azerbaydzhanskomprave(accessed 01 Septemder 2020).

3. Grazhdanskiy kodeks Azerbaydzhanskoy Respubliki ot 28.12.1999 g. № 779-IQ [The Civil Code of the Republic of Azerbaijan ofDecember 28, 1999, no. 779IQ]. Sbornikzakonodatelnykh aktov Azerbaydzhanskoy Respubliki [Collection of Legislative Acts of the Republic ofAzerbaijan], 2000, no. 4, art. 250.

4. Grazhdanskiy kodeks Kyrgyzskoy Respubliki ot 08.05.1996 g. № 15. Ch. I [The Civil Code of the Kyrgyz Republic of May 8, 1996 no. 15 (the First Part)]. URL: http://minjust.gov.kg/ru/content/ 313 (accessed 1 Septemder 2020).

5. Grazhdanskiy kodeks Respubliki Belarus ot 07.12.1998 g. № 218-Z [The Civil Code of the Republic of Belarus of December 7, 1998 no. 218-Z]. URL: https:/ /kodeksy-by.com/grazhdanskij_kodeks_rb.htm (accessed 1 Septemder 2020).

6. Grazhdanskiy kodeks Respubliki Kazakhstan (Obshchaya chast) ot 27.12.1994 g. [The Civil Code of the Republic of Kazahstan (the Common Part) of December 27, 1994]. URL: https:// online.zakon.kz/document/?doc_id=1006061\#pos=5;106 (accessed 1 Septemder 2020).

7. Grazhdanskiy kodeks Rossiyskoy Federatsii (chast pervaya) ot 30.11.1994 g. № 51-FZ [The Civil Code of the Russian Federation (the First part) of November 30, 1994 no. 51-FL]. Sobraniye zakonodatelstva RF [Collected Legislation of the Russian Federation], 1994, December 5 (no. 32), art. 3301.

8. Grazhdanskiy kodeks Ukrainy ot 16.01.2003 g. № 435-IV [The Civil Code of the Ukraine of January 16, 2003 no. 435-IV]. URL: https:// kodeksy.com.ua/ka/grajdanskij_kodeks_ukraini.htm (accessed 1 Septemder 2020).

9. Ochkhaev T.G. Izmeneniye i rastorzheniye dogovora $v$ svyazi s sushchestvennym izmeneniyem 
obstoyatelstv: dis. ... kand. yurid. nauk: 12.00 .03 [Amendment and Dissolution of the Contract Due to a Substantial Change in Circumstances. Cand. jurid. sci. diss.]. Moscow, 2015. 249 p.

10. Sosipatrova N.E., Burova A.Yu. Tolkovaniye grazhdansko-pravovykh dogovorov v zarubezhnoy i rossiyskoy pravovykh sistemakh [Interpretation of Civil Law Contracts in Foreign and Russian Legal Systems]. Vestnik Nizhegorodskogo universiteta im. N.I. Lobachevskogo. Seriya: Pravo [Bulletin of the Lobachevsky University of Nizhny Novgorod. Series: Law], 2018, no. 1, pp. 122-129.

\section{Information About the Authors}

Mohammed Vidad Abdulhamid Alhamdawi, Postgraduate Student, Department of Business Law, Arbitration and Civil Procedure, Volgograd State University, Prosp. Universitetsky, 100, 400062 Volgograd, Russian Federation, laweyerm@yahoo.com, https://orcid.org/0000-0002-7614-8453

Maxim M. Nenashev, Candidate of Sciences (Jurisprudence), Head of the Department for Work with State Bodies and Resolution of Administrative and Legal Disputes, PAO "Nizhnekamskneftekhim", Sobolekovskaya St, Bld. 23, Office 129, 423574 Nizhnekamsk, Russian Federation, netnashev@mail.ru, https://orcid.org/0000-0002-8160-0520

\section{Информация об авторах}

Мохаммед Видад Абдулхамид Альхамдави, аспирант кафедры предпринимательского права, арбитражного и гражданского процесса, Волгоградский государственный университет, просп. Университетский, 100, 400062 г. Волгоград, Российская Федерация, laweyerm@yahoo.com, https://orcid.org/0000-0002-7614-8453

Максим Михайлович Ненашев, кандидат юридических наук, начальник отдела по работе с государственными органами и разрешению административно-правовых споров, ПАО «Нижнекамскнефтехим», ул. Соболековская, здание 23, офис 129, 423574 г. Нижнекамск, Российская Федерация, netnashev@mail.ru, https://orcid.org/0000-0002-8160-0520 